\title{
RESEÑAS CRÍTICAS DE LIBROS
}

\section{Nonhuman Photography, Joanna Zylinska}

\author{
Deni Xiadani Garciamoreno Becerril \\ Universidad Iberoamericana Ciudad de México \\ México
}

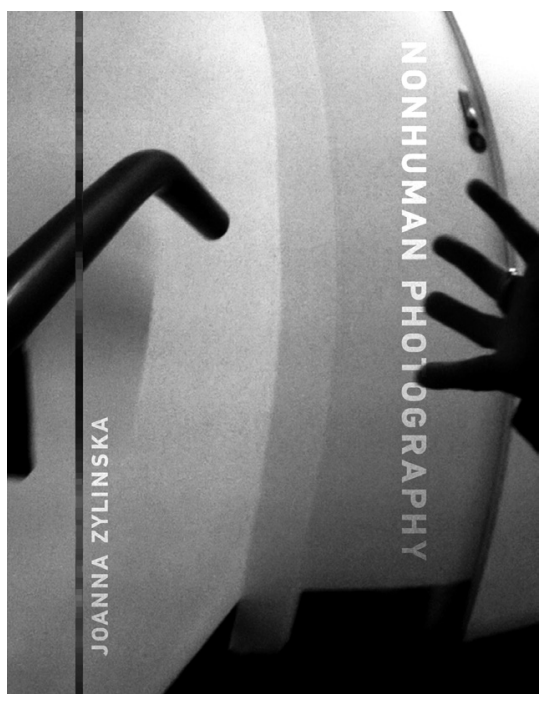

Joanna Zylinska, Nonhuman Photography. Cambridge: The MIT Press, 2017.
En los últimos años, la fotografía y los aparatos que la posibilitan han representando, más que una novedad, un reto para los humanos, puesto que modifican vertiginosamente nuestra relación con el mundo. Las nuevas tecnologías y aparatos al alcance de nuestras manos parecen no sólo provocar que la fotografía configure con mayor capacidad nuestro mundo, sino que esta particular configuración se extrae a partir de estas nuevas tecnologías y posibilidades.

Precisamente, Joanna Zylinska aborda esta problemática en su libro Nonhuman Photography. La autora afirma que: "[e]n la agencia humana-nohumana conjunta, la fotografía funciona como una forma de control y como una fuerza que moldea la vida". ${ }^{1}$ Aquí hay dos elementos inte-

${ }^{1}$ Joanna Zylinska, Nonhuman Photography (Cambridge: The MIT Press, 2017), 2. [todas las tra- 
resantes que nos invitan a pensar $y$ repensar las nuevas tecnologías. En primer lugar, Zylinska resalta la duplicidad entre las formas humanas y no humanas de la fotografía. En segundo término, la autora delinea las fuerzas que estas formas de fotografía pueden tener en lo humano: de control y configuración de la propia vida o de las formas de vida en nosotros. Esta afirmación en las primeras páginas de Nonhuman Photography no es una cuestión menor, pues marca la pauta y la verdadera relevancia de repensar la fotografía tal y como Zylinska lo propone: como aquella fuerza no humana que, de forma paradójica, delimita nuestras propias maneras de vivir.

Nonhuman Photography plantea como problemática general que incluso las imágenes producidas por el humano o posibilitadas en su dimensión técnico-creativa por los humanos implican, en un inicio, un elemento no humano. A partir de este postulado es que Zylinska permite pensar la fotografía como aquello que ha moldeado nuestras políticas de la visión y que, por lo tanto, predetermina la relación de superioridad que tenemos con el mundo y la naturaleza.

La autora se posiciona en una reflexión poshumanista la cual, a partir de la proliferación de contenido digi-

ducciones están hechas por la autora de esta reseña] tal, permite pensar la fotografía como un elemento constitutivo de la propia vida humana. Además, contrario a aquella tendencia que ve una pérdida irrevocable de lo humano en las nuevas tecnologías y que mantienen una postura pesimista en relación a esta problemática, Zylinska posiciona la fotografía en su elemento poshumano como condición de posibilidad, para redireccionar la mirada humana y evitar la apropiación del mundo que ésta ha gestado a lo largo de los años. En palabras de la teórica británica: "Nonhuman Photography adopta una perspectiva diferente y probablemente más compleja y multifacética en el tratamiento que le da a la fotografía: el de la teoría poshumanista”. ${ }^{2}$ De esta manera, ella adopta su postura debido a las limitaciones académicas de la teoría clásica sobre la fotografía. Zylinska se posiciona en contra de las reducciones binarias entre humanidad y técnica que han permeado las discusiones académicas. Además, a partir de la necesidad que encuentra de ir más allá de las discusiones hegemónicas, busca un lugar de enunciación desde donde se pueda superar la oposición entre la fotografía como arte y como práctica político-social.

Por ello, Joanna Zylinska se apoya a lo largo de su escrito en producciones artísticas, elementos científicos y experimentos personales que parten

${ }^{2}$ Zylinska, Nonhuman Photography, 4. 
de la fotografía. Afirma que sólo de esta manera interdisciplinaria se puede abordar la fotografía como un conjunto de procesos y no como un objeto aislado de la propia reflexión humana. Los alcances de una reflexión de este tipo permiten pensar el fenómeno de la fotografía de una manera mucho más amplia, pues no se limita a pensar una manifestación artística y un agenciamiento social. La propuesta de Zylinska, en un principio, posibilita pensar la fotografía en el amplio espectro obtenido sobre todo en los últimos años.

La hipótesis central y concreta, a partir de la cual se articulan las diferentes secciones de Nonhuman Photography, es que a partir de la prática fotográfica es posible cambiar la relación que hasta ahora hemos tenido con el mundo. Trastocar la mirada de dios y la posición masculina que han sido determinantes para la explotación de los recursos naturales y el inminente desastre global que se avecina, es posible a partir de los recursos tecnológicos que nos brinda la fotografía. Para sostener esta hipótesis y construir su argumento, Zylinska plantea seis secciones fundamentales para comprender esta relación que, en primera instancia, parecería por completo antiintuitiva para alguien que, de manera especializada, trabaje con cualquiera de estos ámbitos. Para comprender el argumento y visibilizar la línea discursiva del libro es necesario centrarnos en dos ejes centrales planteados en las primeras secciones.

Éstas se inauguran con el primer capítulo: "Nonhuman vision". Lo primero que la autora cuestiona en esta sección es la posición construida para la mirada humana. Contrario a todo naturalismo y a cualquier pensamiento sobre la esencialidad de la visión antropológica, Zylinska nos recuerda que nuestra mirada en realidad está condicionada por agentes no humanos. En esta primera sección la problemática de las nuevas tecnologías se acrecenta, pues éstas no sólo implican agentes no humanos - como Google Earth, los drones y satélites-, sino que también conllevan situaciones donde los humanos somos parte del proceso de visualización, aunque no podamos acceder por nuestros medios biológicos a éste - como la endoscopía y la microfotografía. A partir de este relieve sobre las nuevas posibilidades tecnológicas es que la autora coloca al humano como parte de un ensamblaje de percepción, donde dispositivos orgánicos y tecnológicos comparten los preceptos no sólo funcionales, también estéticos y, sobre todo, políticos. ${ }^{3}$

En este primer capítulo hay tres puntos elementales. En primer lugar, podemos reflexionar sobre el hecho de que existen ciertos elementos tecnológicos que tratan de perfeccionar la

${ }^{3}$ Ver Zylinska, Nonhuman Photography, 14. 
visión humanista (como la endoscopía y la microfotografía). Esta situación, en lugar de propiciar un giro poshumano enaltece aquello que Donna Haraway ha denominado el god trick: una mirada masculina de dominación y ocupación que busca tener poder absoluto sobre las cosas y el mundo. Contrario a esta cuestión, posible gracias a la fotografía, Zylinska encuentra la posibilidad de apertura crítica en el dispositivo fotográfico, precisamente en la nonhuman vision.

Esta visión, que busca desafiar el god trick, nos lleva al segundo punto fundamental que configura la parte central del argumento, sobre lo que la autora llama la no-humanidad inherente a toda visión. A partir de un posicionamiento certero e histórico, logra concluir que "incluso los humanos ven de formas que son más que únicamente humanas". ${ }^{4}$ A lo que se refiere es que aquello naturalizado, a partir de la fotografía, como la visión esencialmente humana, es un constructo que en realidad se puede contraargumentar a partir de varios ejemplos dentro de posibles visiones de los humanos. A partir de este argumento tendríamos la posibilidad de retar la visión tradicional que implica a un sujeto (no a un humano) centrado en sí mismo, masculino, que ha buscado controlar la manera en que generamos una imagen del mundo.

${ }^{4}$ Zylinska, Nonhuman Photography, 17.
Una vez aceptado el segundo punto podemos comprender el tercer argumento que sostiene Nonhuman Photography: el hecho de que, a partir de estas consideraciones, podamos desarollar una visión ecológica de la individualidad. Si la fotografía ha funcionado como dispositivo y aparato que ayuda a formar un god's eye (masculino y dominador), entonces —argumenta Zylinska - podemos reformular esa condición de dominación hacia nuevas maneras de mirarnos a nosotros mismos, y al propio medio ambiente. Esto entraña que, a partir de las posibilidades que una cámara fotográfica nos brinda, podríamos cambiar la condición de una mirada más abarcante y dominadora, virar el rumbo hacia condiciones de visión que nos permitieran - a partir de la reproductibilidad y el acceso a la tecnología no humana- mostrar y, a la vez, configurar nuevos modos de estar con el mundo y vivir en él.

La potencia crítica, ética y política de este libro se encuentra en la relación que la autora genera entre la tecnología y el cambio ecológico, a partir de prácticas artísticas. Si bien su trabajo resulta muy detallado y retrata su preocupación por la práctica artística en otros capítulos, considero que la potencia en relación con un verdadero cambio en el mundo a partir de la fotografía se centra en el segundo y tercer capítulo. En estos, titulados respectivamente: "The Creative Power of 
Nonhuman Photography" y "Photography after the human" se pone en marcha la teorización sobre la fotografía propuesta al inicio del libro.

En principio, Zylinska vuelve sobre la problemática conceptual que una fotografía no humana indica para una investigación de esta índole: apunta que es precisamente en este aspecto de la fotografía que la propiedad creativa y formadora de mundo se puede reconocer. ${ }^{5}$ El elemento no humano de la fotografía no excluye la funcionalidad de las prácticas artísticas o mediáticas fuera de lo humano. Es a partir de su inclusión en la dimensión humana que se abren las posibilidades para cuestionar la soberanía de la agencia humana, la intencionalidad y el posicionamiento subjetivo sobre el mundo propio de la filosofía moderna. Pues bien, la fotografía en este planteamiento permite acomodar un dique sobre la gestión humana que se ha colocado sobre el mundo y lo ha automatizado bajo su propia visión, lo cual sólo nos ha arrojado hacia el borde de una crisis medioambiental. La propuesta se basa en abrir la posibilidad de idear un mundo diferente, poscapitalista, que permita imaginar la muerte simbólica de lo humano para abrirle lugar a una nueva manera de imag(inar) el mundo.

Esta es una lectura indispensable para cualquiera que pretenda teorizar sobre la imagen, el arte, los medios de comunicación y la ecología en un contexto contemporáneo. Nonhuman Photography nos ayuda a situarnos frente a la urgencia ecológica y las problemáticas y posibilidades que las nuevas tecnologías generan. Sólo pensando la posibilidad de la práctica fotográfica en estos términos, la mirada humana se puede transformar hacia una diferente, hacia una historia natural donde nuestra especie acepte su transitoriedad y su existencia en relación con otras determinaciones.

Esta lectura abre una vía para dar respuesta a la relación de la mirada con la técnica, da una respuesta posible hacia las condiciones que tienen que cambiar en nosotros para que la tecnología se exprese de una manera determinada. Zylinska posibilita pensar más allá del giro copernicano planteado en la modernidad. De la misma manera, nos da herramientas para descentralizar y resquebrajar la categoría de sujeto, la cual creó la posibilidad de adueñarse de todo aquello dentro de lo sensible. Nonhuman Photography brinda posibilidades materiales para poner en marcha una sensibilidad ecológico-efectiva, como una práctica facilitada por nosotros mismos, con la potencia de repensar nuestra relación con el mundo: "nos están llamando a reconocer que algo está ocurriendo afuera de nuestro horizonte conceptual y material". 6 